\title{
The contribution of televised sports to the spread of sports activities
}

\section{Paul Irlinger}

\author{
Laboratory of Sociology, Institut National du Sport et de l'Education Physique, 11, avenue du Tremblay, 75012 Paris, France
}

\begin{abstract}
The French public opinion takes for granted that televised sports have played a great part in the expansion of sport practice. This opinion is shared by sport economists, television top experts and leaders of sports organizations.

The statistical data analysis of remit surveys proves that televised sports have only a small influence on the practice and development of sport in France.

Keywords: televised sport, motivation, sport practice.
\end{abstract}

The question dealt with in this paper is "When the viewer watches sport on television does he feel the need to do sport himself, or to do more than he already does?" More generally we will question the role of televised sports events in the spread of athletic activities.

In France, asking such questions seems ridiculous because it seems obvious that televised sports events motivate the viewer to practice more sports. To prove this we cite the waves of young people who go to volleyball clubs after a cartoon like "Jeanne et Serge"" has been broadcast, similarly in Germany the increase in the number of people playing tennis is explained by the impact of seeing Boris Becker and Steffi Graf on television.

This certitude is held not only by the general French public, but also by some of its most famous academics. Vladimir Andreff, the sports economist, who is seen as an authority on the subject in France says "T.V. can condition non-active viewers to feel the need to practice sports, and because of this it contributes greatly to the promotion of sports activities" ,.(Andreff, 1987, 34). Dominique Wolton, a French university lecturer specialising in the analysis of the influence of television, backs up this point of view in writing: "The viewers are not satisfied with being 'armchair players' ; in watching they are often motivated to go and take part" (Wolton 1990, 69). 'This Certitude also seems to be held by the sports movements themselves: the French Basketball Association paid the fees (production colts) for several seasons (up to 1986/7) so that basketball would be seen on the small screen.

\section{From Ideological Certainties to an Objective Approach}

Such general agreement comes from the ideological conviction of the omnipotence of the television. What is ideological in nature is taken for granted and seen as not needing to be proved. In order to be convincing it is only necessary to repeat the ideological discourse, giving some examples if necessary.

The scientific approach needs to have tried and tested knowledge before accepting it and it is not satisfied with what is "obvious" or "not needing to be proved". Providing proof is not an easy thing to do in the Social Sciences, especially when trying to show a cause and effect relation between social phenomenon. Let us add that until 1988 we did not have the data which allowed us to validate what, strictly speaking should have stayed a provisional hypothesis.

The survey, "The sports activities of the French" of 1988 provided the necessary information. Those questioned were asked in depth both about their sports activities and their interest in sports programs. This allowed for a quantitative approach to the relation between watching televised sport and the practice of sports or physical activities. 
"The sports activities of the French"

(INSEP survey)

SAMPLE: 3000 people between the ages of 12 and 74. Chosen according to the quota method developed by the Institut National d'Etudes Démographiques (INED), this included region and city size stratification.

IN THE FIELD: the survey was carried out in November and December 1985 by INED researchers (interviewers).

FUNDING: this was provided by the Ministère de la Recherche et de l'Enseignement Supérieur (Ministry of Research and Higher Education) (file $\mathrm{n}^{\circ} 84 \mathrm{D} 1581$ ) and the Ministère de la Jeunesse et des Sports (Ministry for Youth and Sports).

DESIGN, REALISATION AND DEVELOPMENT: Sociology Laboratory of the Institut National du Sport et de l'Education Physique (National Institute of Sports and Physical Education) (INSEP).

PUBLICATION: IRLINGER (P), LOUVEAU (C), METOUDI (M). — The Sports Activities of the French. — INSEP, Paris, 1988. - 2 vol., 730p.

\section{Between the Screen and the Field, a Weill Established Link}

Through mass media sports culture has become omnipresent: even those who are not interested in sport cannot escape it. Those who do not practice sports themselves are included in this facet of modem day life. $58 \%$ of them watch sports programs at least occasionally while the figure for those who take part in sports is $75.8 \%$. This highly significant difference proves that playing sports and watching sports programs are statistically linked. ${ }^{2}$

The statistical analysis shows that the strength of this relation varies according to different types of sport or physical activity. The percentages of people who watch sports programs at least occasionally are:

$-72.1 \%$ for people who only do sport during the holidays, against,

- $80.6 \%$ for those who do it all year long;

- $73.6 \%$ for those who practice a sport less than once a month, against,

- $86.7 \%$ for those who do a sport more than three times a week (table 1).

Table 1 Watch sports programmes at least occasionally

$58.1 \%$ of those who do not do any sport

$73.6 \%$ of those who do it less than once a month

$75.4 \%$ of those who do it once or twice a month

$80.1 \%$ of those who do it once a week

$82.9 \%$ of those who do it twice or three times a week

$86.7 \%$ of those who do it more than three times a week

These differences become even more marked if we take into account the degree of institutionalization of the activity (table 2).

Table 2. Watch sports programmes at least occasionally

$92.1 \%$ of participants who have licenses and take part in competitions

$82.6 \%$ of participants who have licenses and take part in the activity

$71.4 \%$ of non-licensed participants who take part in the activity

$70.9 \%$ of those who do keep fit or sports for health reasons

$58.1 \%$ of those who do not do any sport

Highlighting a statistical link between two variables and establishing a covariance lets us conclude that there is a causal relationship but we cannot be more precise as to its nature or meaning.

The fact that the percentage of "viewers active in sports" varies with the existence, continuity, frequency and level of the institutionalization of their sports and physical activities does not allow 
us to conclude that watching televised sport motivates people to take up sports, to do more sport, or to do sport within an organized system. We could just as well draw the inverse conclusion, i.e. that doing an activity creates an interest in televised sport, or that the practice and watching of sport are affected by a third variable.

To resolve this uncertainty we must turn to other information, pass the stage of making an inventory of the practice and try to take into account the real life of those who practice sports. Going beyond the purely factual data, the INSEP survey on the sports activities of the French provides more subjective data which allows us to explore the relationship between sports activity and televised sport more deeply.

\section{What do People Feel when Watching Sport on the Television?}

Through the INSEP survey we tried to explore the social pressure concerning sports activities and the way people internalize it. The answers to question 91 (table 3) revealed the existence of a feeling, a need, almost a moral necessity, to take part in sports and physical activities.

\section{Table 3.}

Question 91: Do you ever feel that you should do some sport or that you have to do more?

$$
\text { NO } 1
$$

YES 2

If YES, in what circumstances does this occur? (Please answer clearly)

Three out of five answered "YES", but watching televised sports is low on the list of circumstances in which this occurs (figure 1).

\section{Figure 1}

\section{Circumstances in which you feel you should do some sport or do more}

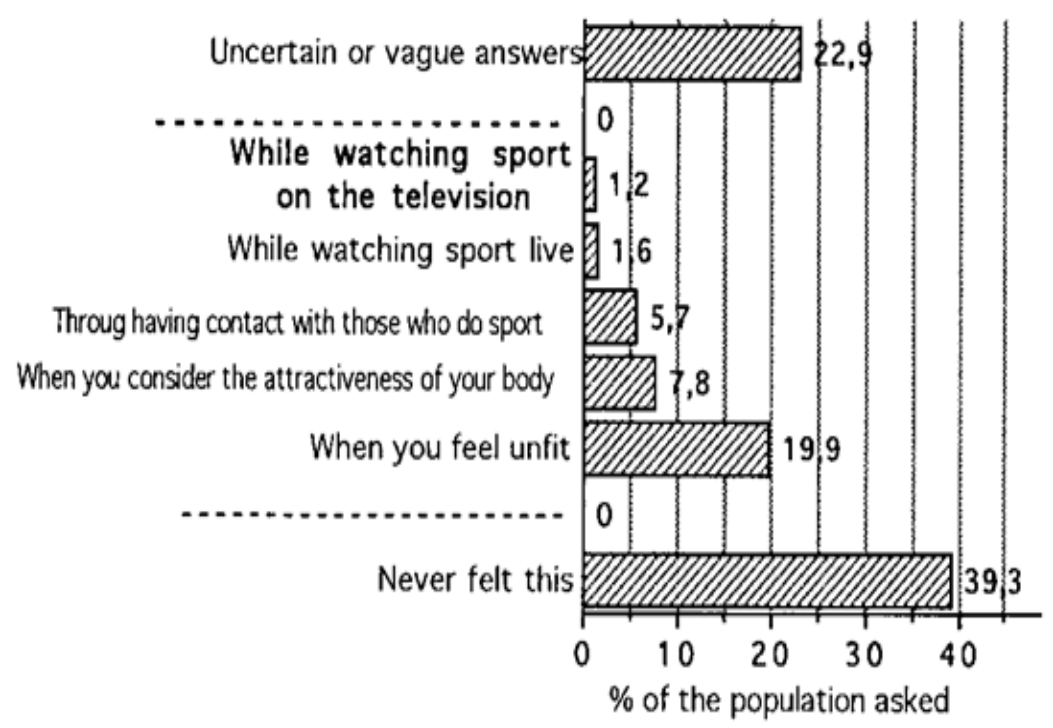


We cannot help but be surprised by such a small percentage, even if we do not believe in the omnipotence of the small screen. Although nearly three out of four French people occasionally watch televised sports only $1.2 \%$ of them feel the need to take part in a sport or to do more sport while doing this.

The publication of this result provoked violent protest. Some spoke for the strong influence of televised sport on young people. The figures for young people aged from 12-17 do show that they are more likely to be motivated to engage in sport by watching television than the rest of the population: $2.6 \%$ of them felt this. But even for this group the results are not what we expected.

Others complained about the form of the question, saying it should not have been open-ended. It is true that television has become so accepted and integrated into everyday life that it has become almost invisible. It is possible that when answering question 91, which is not a multiple choice question, people forgot to mention television.

A more recent survey on the sports and physical activities of the Parisians ${ }^{3}$, contained a question very similar in meaning to ours (Figure 2). But this was not an open ended question, it was multiple choice. The designers of this survey had placed "You saw it on T.V." at the top of this list of possible answers, which shows what they were expecting as a reply, we can imagine their surprise when they saw the results.

Figure 2.

Which of the following reasons would motivate you to take up a sport?

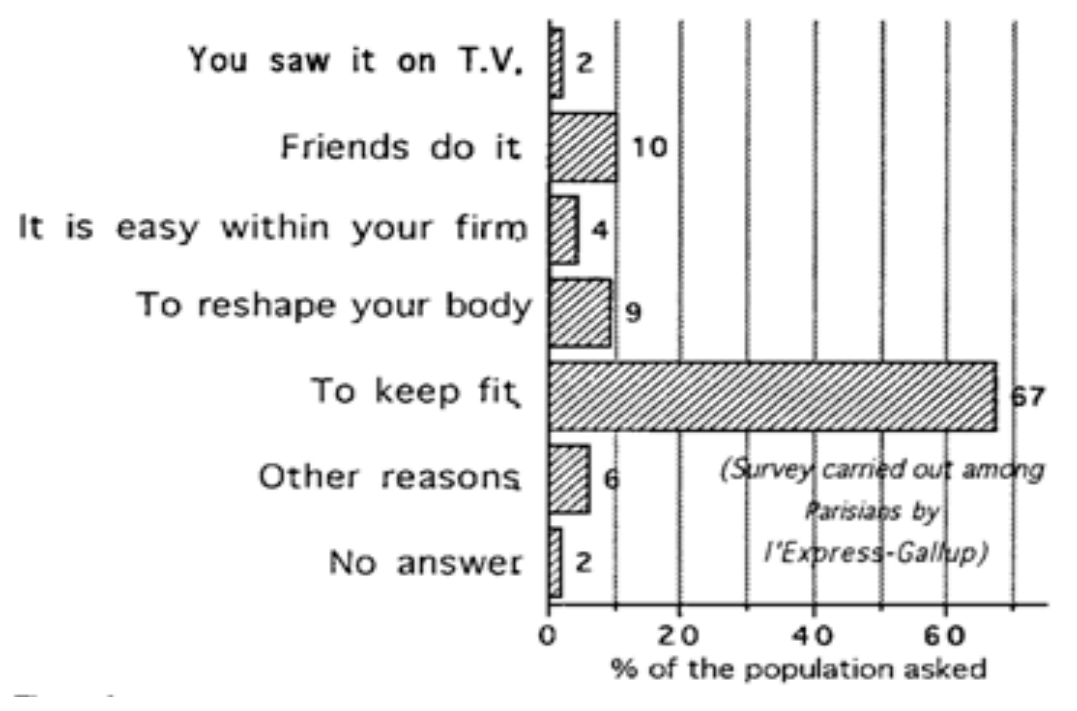

We must accept the proof: televised sport does not have the effect we thought it had.

It is only a very small minority who feel motivated to engage in athletic activity when watching sports programs, whether we take this as $1.2 \%$ or $2 \%$.

Among those who "feel they should do a sport" or "could be motivated to do a sport" how many actually do this, either by taking up a sport, increasing their physical activity, or doing so more regularly?

One last question should be raised: what about unconscious influence? It is possible that someone questioned during the survey answered "no" in all honesty, but in fast had been influenced without being aware of it. In order to investigate such unconscious influences we must turn to clinical psychology. 


\section{The Opinion of those who practice a sport}

Pascal Duret, in a survey involving volleyball players between 8 and 13 (1991) years old, asked, "How did you discover volleyball?" 40\% chose the answer "through television". But among those who had given this answer only $8 \%$ could name a national team member, while $100 \%$ of them knew the cartoon "Jeanne et Serge" which tells of the romantic and sports adventures of a young girl who plays volleyball. Therefore among these young volleyball players, $3.2 \%(8 \%$ of $40 \%)$ are likely to have come to volleyball through the influence of seeing it on television.

Sports programs' Jack of effect in motivating people is confirmed when we question those who play tennis, the sport which has the most T.V. coverage in France. In depth interviews with tennis hopefuls who had received help from the tennis association led to the same conclusion: when remembering how they had started out, they did not cite television as one of the elements having motivated them to take up tennis, even when this question was specifically put to them. Here, we are no longer concerned with the potential practice of a sport but a real situation, in which what is practiced is pretty close to what is seen most on television: international tournaments. We might have expected that these "hopefuls", would have been particularly affected by televised sport, but they are not.

We must note that for the past few years the Fédération Française de Tennis (F.F.T.) has been advertising on television during the Roland Garros tournament. These adverts have featured an intelligent mix of beginners, everyday players and champions. The F.F.T. seems to have understood that to get people to take up tennis and to join clubs it is not enough just to show high level tennis on T.V.

Does this mean that televised sport has no ability whatsoever to encourage people to take up a sport? That is not what we claim here.

Under certain circumstances, exceptional events can have unusual effects. One such event was the almost simultaneous appearance of Steffi Graf and Boris Becker at the highest levels of international sport. This was celebrated by the West German public T.V. stations. The F.R.G. had never before had tennis champions and there were only relatively few players. The high profil given by the media to the success of these two champions was therefore a first for a large, unsaturated potential public. Such spectacular but short-lived and localized effects, limited to one sport, are perfectly compatible with a general average of $1.2 \%$ to $2 \%$ for people influenced.

We must remember that the 'bottom line for sports programmes is strictly economic, and that they are subjected to the general male of viewer ratings. The motivating influence is only a sideeffect, a sort of accidental by-product.

\section{What are Effective Motivations Today?}

We cannot, therefore, count on televised sport to spread the practice of sports and physical activities. The INSEP and "Express" surveys show that what motivate people to take up a sport nowadays is their concern about being in shape, whether this is connected to "well-being"; "worry about the state of vital organs" and suppleness of movement; or to "looking good", "the figure" and the shape of their body. Here we meet, at a corporal level, the modern-day process of personalisation which affects all advanced democratic societies in the post-modern era (Lipovetsky 1983).

However, there is also an infectious effect (cf. figures 1 and 2), seen in the results for "friends who do it" (Express) and "through having contact with those who do it" (INSEP). Sport is "caught" both from those who are close to us and from activities which seem accessible by their nature and level. This closeness is in contrast to what we see on television.

But there is another difference which puts an even greater separation between "ordinary sport", with which we have concrete experience either personally or through those close to us, and sport 
that we see on the small screen. This is the result that television has on sport. ${ }^{5}$

\section{Always More Spectacular}

When television began broadcasting from sports stadiums it was content with covering important sporting events, giving a true picture of what was happening by presenting both a radio report and a cinematographic image. The camera, situated at the half-way line in the football field showed, in black and white, what a spectator at that point would have seen. This kind of sports coverage has gradually changed with the technological development of the equipment and by the evolution in production techniques. This change has been amplified and accelerated by the increase in the number and the privatization of the channels engaged in the war for viewer ratings. The camera does not now limit itself to replacing a spectator but transforms what the spectator sees. Using zoom and playing with distance transports the viewer into forbidden territory, to the heart of the action. The increased number of cameras, giving multiple points of view has given rise to the ubiquitous and omnipresent spectator. The introduction of portable cameras which can move on rails let this fictitious spectator move. ${ }^{6}$ Overhead cameras' transform him into a hyperspectator. Only Icarus could have had such a view. Microphones which follow the action, hidden under the coach's bench or lying in wait behind the goal posts, pick up and relay sounds which no physical spectator present in the stadium could hear. The restraint of the linear passing of time is also overcome and perverted by slow-motion and action replays, which are multiplied by the various positionings of the cameras and which capture for eternity the joy of the winning goal.

The necessity of attracting and keeping the most viewers possible, feverishly measured in audience scores and shares of the market, takes over the producers' imagination, committing them to a lost quest for new special effects. ${ }^{8}$ In France the introduction of basketball to television was done with "close-ups of the mass of hands trying to get the ball from a rebound and slow-motion smashes which get you right in the face", (Thomas 1988, 36-39) thanks to cameras behind transparent panels.

Televised sport is now no more than pure spectacle, superbly done, which brings together a density and variety of actions, effects and emotions which only have a distant relation to what an ordinary player or spectator can experience. Hence, there is a world of a difference between sport and its televised image. We can easily see that televised sport is more inclined to encourage imaginary practice than to motivate people to real practice. ${ }^{9}$

\section{Notes}

${ }^{1}$ Most of the action in this cartoon, imported from Japan, is centered on volleyball. This is a cartoon and fictional; it is not televised sport.

2 To 0.001 . These figures are taken from the survey "The sports activities of the French" (cf. table 1).

${ }^{3}$ Survey done for "L'Express" by "Gallup-Faits et Opinions" in March 1986 with a sample of 505 people representative of the Parisian population, aged between 18 and 64. In: "L'Express de Paris" 18-24 April 1986.

4 This concerns research work done by Catherine Humblot with the help of the Fédération Francaise de Tennis, aimed at find out what had become of old "hopefulls" and to improve the help the federation could give to these players.

${ }^{5}$ For a more complete analysis see Charles Tesson "Filmer le sport" in the article "Sport" in the 1989 edition of the Encyclopaedia Universalis. 
6 This was Pierre Salivac's idea, put into practice by the SFP technicians and used during the France-Wales rugby match in the 1989 Five Nations tournament. the rails were behind the goals and allowed for close-up filming of head-on attacks to be shown in slow-motion. During the same match, for the first time, a camera was mounted an a crane 63 meters above the pitch at Parc des Princes.

${ }^{7}$ See the end of the previous note.

8 The drop in public interest for sports programs noted by the B.V.A. surveys for TF1 in 1975, 1980 and 1984, and confirmed by the INSEP survey, makes this a lost cause which only accelerates the saturation effect of televised sport.

9 The INSEP survey asked the question: "Given the financial situation, health, time and necessary equipment, which sport would you dream of doing?" In comparing this "hit-parade" of sports to the "hit-parade" of sports people really do, we note that with the exception of cycling, sports shown, transfigured and magnified by the television are classed much higher on the list of dream sports than in sports actually done. These dreams are probably the result of psychological projection mechanisms and identification with sports heros seen on television.

\section{References}

ANDREFF, W, NYS, J.F., 1987: Le sport et la télévision: relations économiques: plurialité d'intérets et sources d'ambiguitiés. Daolloz, Paris. Coll. Droit et Économie du sport.

DURET, P., 1991: Les représentations sociales du Volleyball. Thesis for INSEP diploma. INSEP, Paris.

LIPOVETSKY, G., 1983: L'ère du vide - Essais sur l'individualisme contemporaine. Gallimard. Paris.

THOMAS, JL., 1988: "Cette fois c'est Show". L'Equipe Magazine No. 358 of March 12th, 1988, pp. 36-39.

WOLTON, D., 1990: Eloge du grand public, une théorie critique de la télévision. Flammarion, Paris, p. 69. 